\title{
Performance Evaluation on Aquatic Product Cold-Chain Logistics
}

\author{
Wenbing $\mathrm{Wu}^{1}$, Yanwei Deng ${ }^{1}$, Mingyu Zhang $^{1 *}$, Yihua Zhang ${ }^{2}$ \\ ${ }^{1}$ School of Economics and Management, Beijing Jiaotong University, Beijing 100044, P.R. (China) \\ ${ }^{2}$ Department of Economics, University of California, Santa Cru₹, CA 95064 (U.S.A.) \\ wenbingwu@263.net, dengyanwei@,126.com,mingvushang@263.net,_ihbuazhang@yeah.net
}

Received: November 2015

Accepted: December 2015

\section{Abstract:}

Purpose: The requirements for high quality and diversification aquatic products are increasing with the improvement of Chinese living standard. However, the distribution between the place of production and the place of consumption are uneven, which results in large cold-chain logistics demand for aquatic products. At present, the low-level development of cold chain logistics has a bad impact on the circulation of aquatic products in China. So it is very urgent to develop cold-chain logistics in China.

Design/methodology/approach: In order to do this, we apply performance evaluation, a well-known management tool, to study Chinese aquatic product cold-chain logistics. In this paper we first propose SISP (Subjects, Indexes, Standards, and Phases of performance evaluation) model and ACSSN model (Aquatic product, Customer, Supply Chain, Society, and Node enterprises of supply chain) for aquatic products cold-chain logistics performance evaluation. Then an ANP-Fuzzy method is proposed to evaluate the operational performance of Shandong Oriental Ocean Sci-Tech Co., Ltd. Furthermore, a system dynamic model is built to simulate the impact of temperature on the profits in aquatic products cold-chain sales section. 
Findings: We find out within a reasonable temperature range, lower temperature brings higher profit level. Also, performance improvement methods are proposed and the simulation of performance evaluation system is developed.

Practical implications: Our findings can help to improve the level of aquatic product coldchain logistics in China.

Originality/value: The paper proposes the SISP (Subjects, Indexes, Standards, and Phases of performance evaluation) model and ACSSN model (Aquatic product, Customer, Supply Chain, Society, and Node enterprises of supply chain) for aquatic products cold-chain logistics performance evaluation.

Keywords: aquatic products, cold-chain logistics, performance evaluation, performance improvement

\section{Introduction}

Until 2012, the output of Chinese aquatic production has ranked first in the world for 23 years. The volume per capita amounted to $43.63 \mathrm{~kg}$. However, the production of aquatic products shows obvious regional characteristics in China. This leads to the differences in consumption habits and consumption preferences at difference region. Data from questionnaire shows that the expenditure proportion for aquatic products in the household food consumption are respectively $24 \%, 17 \%$ and $13 \%$ in Shanghai, Beijing and Xian (Sun, Wang \& Zhang, 2015). Aquatic product, as a high-protein and high-nutrition food, is very popular and the consumption increases quickly. Because of the vast territory of China, the requirement for diversity and high quality aquatic products will results in multitudinous and long distance logistics. As a highly perishable product, aquatic products need the whole-chain support of cold-chain. But cold-chain logistics in China is still in its infancy. Its efficiency is low, its loss rate is high, and its product quality safety can't be ensured. At the same time, the high logistics costs leads to high sales price of aquatic products. Therefore, how to promote Chinese aquatic products cold-chain logistics has become an important issue faced by the firms in China.

Performance evaluation plays an important role in improving the performance of aquatic products cold-chain logistics. It can improve operational efficiency, reduce logistics costs, identify problems in time, and take timely improvement measures. It also can provide reference for aquatic products cold-chain logistics enterprises' decision making. Therefore, aquatic products cold-chain logistics performance evaluation has practical significance in promoting Chinese aquatic products cold-chain logistics. 
The rest of the paper is organized as follows. First, literature related to this research is reviewed. Then, we state the performance evaluation system for aquatic products cold-chain logistics. In Section 4, an empirical research is conducted by using the operational data of an aquatic products enterprise in China. In Section 5, a system dynamics model is built to verify the effect of maintaining a lower logistics temperature for performance level.

In this paper we propose SISP (Subjects, Indexes, Standards, and Phases of performance evaluation) model and ACSSN model (Aquatic product, Customer, Supply Chain, Society, and Node enterprises of supply chain) for aquatic products cold-chain logistics performance evaluation. We find out within a reasonable temperature range, lower temperature brings higher profit level. Also, performance improvement methods are proposed and the simulation of performance evaluation system is developed.

\section{Literature Review}

The first line of literature related to this study is on cold-chain logistics. Dabbene, Gay and Sacco (2008) developed a hybrid model to optimize the fresh food supply chain under uncertainty, to balance logistics costs and indicators affecting food quality such as maturity, microbiological control, temperature and others. Zanoni and Zavella (2012) studied the relationship between the temperatures setting, the effect of temperature on products quality, energy consumption and corresponding costs. Van Donselaar and Broekmeulen (2012) pointed out that retailers are keen to reduce the number of expired perishable products because the waste of expired perishable goods not only means the materials loss but also bring an increase in the supply chain transportation costs, labor costs and waste of social resources.

The second line of literature related to this study is on logistics and supply chain performance evaluation. Fawcett and Cooper (1998) conducted a longitudinal empirical research on more than 100 world's top logistics companies and found out that an excellent performance evaluation system is essential to achieve high performance. Wong (2008) considered benchmarking as a powerful management tool that can help organizations to establish best performance standards within the industry and promote the organization for continuous improvement. Garcia, Marchetta and Camargo (2012) proposed a logistics benchmarking framework for the wine industry. Jacxsens, Luning, Marcelis and van Boekel (2011) established a set of integrated tools for food safety management system: performance diagnosis, selection, and performance improvement.

As for performance evaluation indexes, Bowersox (1996) argued that the performance of logistics enterprises can be evaluated from both internal (costs, customer service, productivity rate, and quality) and external (customers feeling measure, best practices). Aramyan, Oude Lansink, van der Vorst and van Kooten (2007) considered that the selection of appropriate 
cold-chain performance evaluation indexes is quite difficult because it is a typical multi-input and multi-output system. Jacxsens, Uyttendaele and Devlieghere (2010) developed a set of food safety performance management diagnostic system for strict and specific evaluation, which can yield better performance for the assumption. Joshi, Banwet and Shankar (2011) selected the costs, quality and safety, service levels, traceability, return on assets, innovation and customer relations as the evaluation indexes using Delphi-AHP-TOPSIS method, and constructed a cold-chain performance evaluation system based on benchmarking framework.

Summarizing above, we found that there are few special studies on the aquatic products coldchain logistics performance evaluation in existed literature, and the results of these studies are relatively fragmented. Therefore, according to the characteristics and goals of aquatic products cold-chain logistics, we propose innovatively the SISP (Subjects, Indexes, Standards, Phases of performance evaluation) model for aquatic products cold-chain logistics performance evaluation system and ACSSN (Aquatic products, Customer, Supply chain, Society, Node enterprises of supply chain) model of performance evaluation indexes based on traditional performance evaluation system. Then we use "Fuzzy Comprehensive Evaluation Method" to evaluate the operation performance of an enterprise engaged in aquatic products in China, put forward the improvement measure of keeping lower logistics temperature and develop a system dynamics model to simulate the performance. Different from the existing researches, this paper constructs a complete framework for aquatic product cold chain logistics performance evaluation. It highlights the characteristics and the aim of aquatic product cold chain logistics, and has more realistic guidance significance for the development of aquatic product cold chain logistics in China.

\section{Performance Evaluation System for Aquatic Products Cold-Chain Logistics}

\subsection{The Characteristics of Aquatic Products Cold-Chain Logistics}

\subsubsection{High Requirements for Logistics Temperature}

The processing environments and the microbial activities determine together the quality of aquatic products which are easy to spoilage in the logistics process. Temperature is the most critical factor affecting microorganisms' growth. Meanwhile, low temperature has an obvious inhibitory effect on enzyme activity which accelerates the resolving of proteins and fats. Moreover, the "3T" principle in cold-chain logistics points out that the decline in food quality is cumulative and irreversible, and is irrelevant with the order of quality decline. So, it is necessary to keep lower temperature in entire cold-chain logistics process to ensure the quality of aquatic products. 


\subsubsection{High Requirements for Supply Chain Coordination}

Different technical specifications of cold-chain logistics equipments, temperature fluctuations and time lags at different logistics links, and isolated information generated from subjective or objective factors should be coordinated closely between upstream and downstream enterprises. In addition, numerous logistics links and subjects, and lower degree of organization increase the difficulty of coordination.

\subsubsection{High Comprehensive Cost of Logistics}

The high infrastructure costs of cold-chain logistics, incurred by stiff price and specificity of facilities, the large energy consumption for low temperature, and the high quality loss cost increase the comprehensive costs of logistics. This is a major issue for the development of aquatic products cold-chain logistics and aquatic products consumption in China.

\subsection{SISP Performance Evaluation Model}

The traditional performance evaluation system can evaluate performance within its scope primely. But aquatic products cold-chain logistics has inherent specificity. In the determination of evaluation objectives, the selection of evaluation indexes and the performance improvement, the traditional performance evaluation system has some limitations. Therefore, we combines the aquatic products cold-chain logistics characteristics and the subjectives involved in cold-chain to propose the SISP four dimensions evaluation model, including the evaluation subject, evaluation indexes, evaluation standard and evaluation phase, to construct aquatic products cold-chain logistics performance evaluation system. 


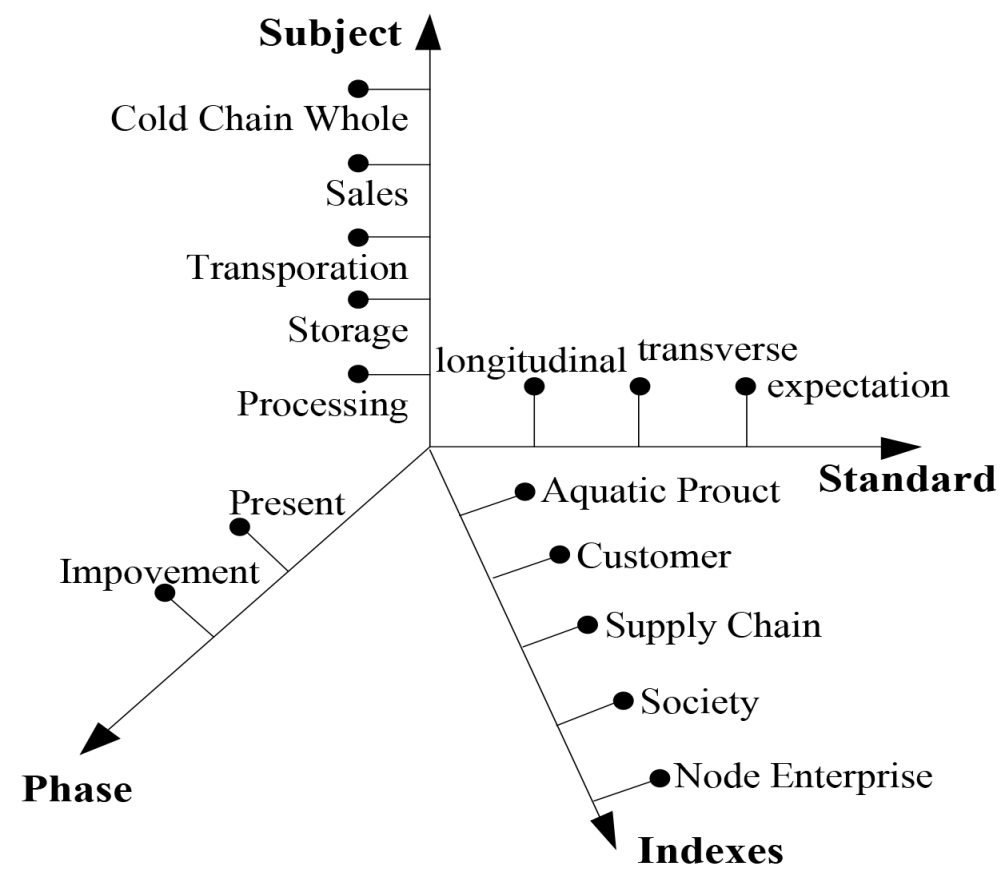

Figure 1. The SISP performance evaluation model

\subsubsection{Evaluation Subject}

It is well known that supply chain management emphasizes the optimal overall performance of the supply chain. However, aquatic products cold-chain logistics is a special chain and evaluating the aquatic products cold-chain logistics only from the overall perspective will lead to the following issues: First, the supply chain is actually a virtual organization which consists of independent entities. Each of node enterprises has its own strategic objectives and concerns. Aquatic products cold-chain logistics overall performance cannot fully reflect the demand of each node enterprise. Second, the performance is the sum of the processes and results and the overall performance cannot emphasize on the performance execution detail and coordination efficiency of each link. So it is difficult to find the causes of performance increase or decrease, and unable to develop highly targeted performance improvements methods. Third, the overall performance cannot reflect the individual enterprise's performance and the contribution for the overall competitiveness enhancement.

According to "Agricultural products cold chain logistics development planning" issued by China's National Development and Reform Commission, cold-chain logistics is divided into four links: cold- chain processing, cold-chain storage, cold-chain transportation and distribution, and cold-chain sales. Therefore, we select the aquatic products cold-chain processing, coldchain storage, cold-chain transportation and distribution, cold-chain sales, and aquatic products cold-chain overall operation as the evaluation subjects. 


\subsubsection{Evaluation Indexes}

The design of performance evaluation indexes is the first thing in performance evaluation. The indexes are the most direct carrier to achieve the objective of aquatic products cold-chain logistics. Aquatic products cold-chain logistics needs to meet the benefit demands of the participants, including aquatic products itself, customers, supply chain, society, and cold-chain logistics node enterprises. We select evaluation indexes based on the 5 aspects.

\subsubsection{Evaluation Standards}

Setting performance standards can deliver an organization's strategic intent. Thus, choosing exactly what kind of performance standards has great impact on the implementation of the performance evaluation. Here we think that the nature of the performance evaluation is actually a comparison process, i.e., the actual performance is compared with some performance standards. The comparison process is available from the following three perspectives: longitudinal comparison, transverse comparison and expected comparison. Longitudinal comparison is to compare the performance of enterprise's own historical performance. Transverse comparison is to compare with the similar enterprises. The available comparison standards can be the benchmarking performance or average performance of an industry. If there is no clear performance criteria, sorting transverse between evaluation objects is also a choice. Expected comparison contrasts the actual performance with the expected performance. The standards can be customer's expectation performance, performance plans, and national or industry standards.

\subsubsection{Evaluation Phase}

As we know, most current researches on performance evaluation only study the evaluation of present performance, and few literature consider performance improvement. Since the original purpose of performance management is continual performance improvement, the improvement measures are needed, and the simulation of performance improvement methods should become an essential part of the performance evaluation process. Therefore, we not only evaluate the current performance of cold-chain logistics (the first evaluation phase), but also propose appropriate performance improvement measures and simulate the improvement measures using appropriate method (the second evaluation phase). 


\subsection{ACSSN Model for Performance Evaluation Indexes}

It is well known that there are Key Performance Indicators, Balanced Score Card and other methods for the design of performance evaluation indexes. These methods have a positive effect on the evaluation of individual enterprise, but limitations for evaluation of the organizations across corporate boundaries such as aquatic products cold-chain logistics. The Supply Chain Operation Reference Model (SCOR) is specifically designed for supply chain management including the supply chain performance evaluation, but it is lack of adaptability to aquatic products cold-chain logistics performance evaluation because it is based on manufacturing industry supply chain. There are many researches about logistics performance evaluation, but the evaluation indexes system and framework model recognized by the industry has not taken shape. In order to deliver the objectives of aquatic products cold-chain logistics clearly and reflect its specificity, we propose an aquatic products cold-chain logistics performance evaluation ACSSN model, which is shown in Figure 2.

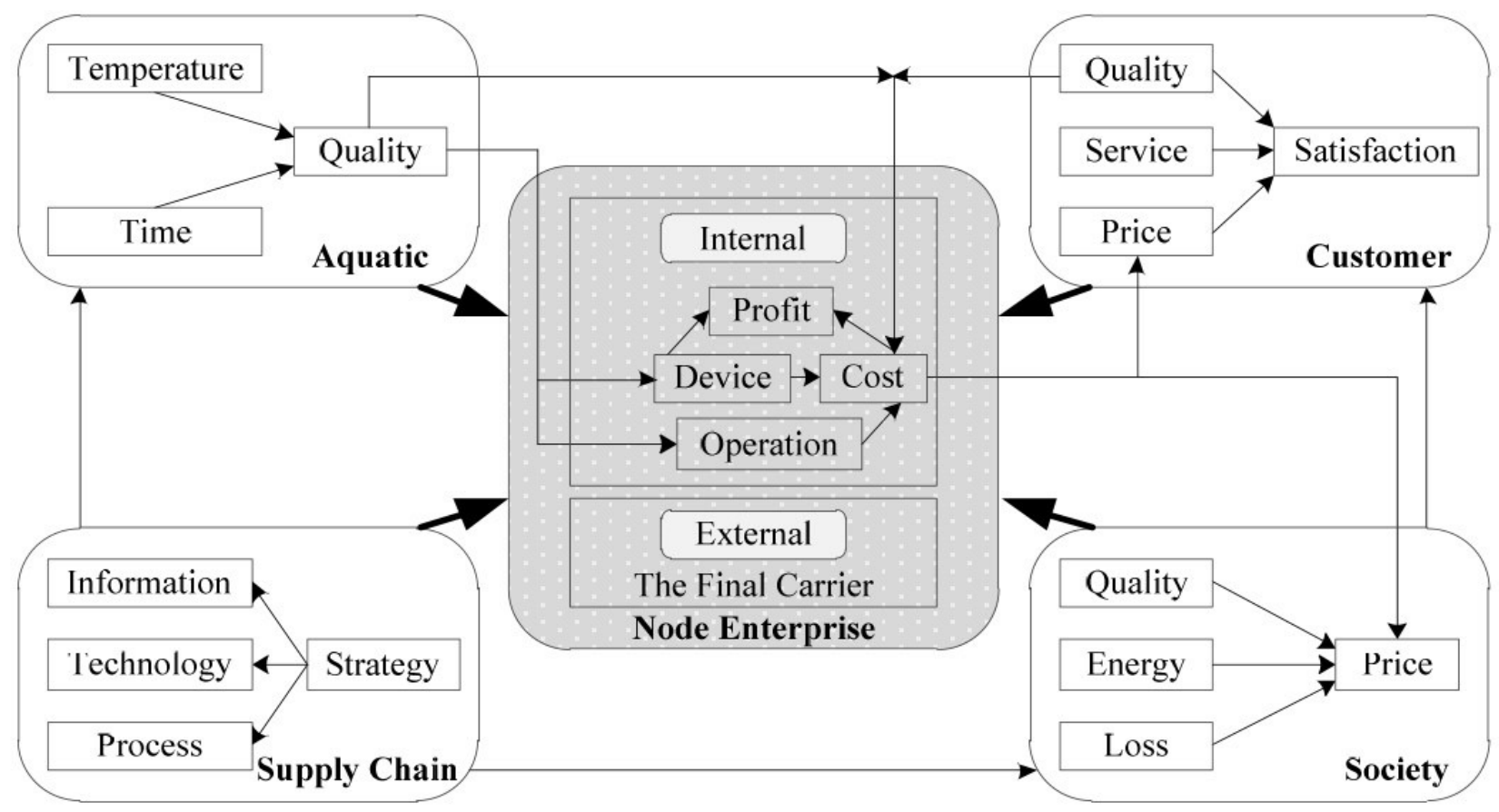

Figure 2. The ACSSN model

We think that the design of aquatic products cold-chain logistics performance indexes should take into account the goals and benefits of the participating subjects in the cold-chain logistics. It should balance the economic benefits and social benefits, cost saving and efficiency increasing. Thus, we designed the performance evaluation indexes from 5 aspects: aquatic product, customer, supply chain, society, node enterprise of supply chain. These five aspects (ACSSN), interacting and restraining one another, will be discussed below in detail. 


\subsubsection{Aquatic Products Indicators}

For aquatic products, the most critical indicator is the quality. According to the " $3 T^{\prime \prime}$ principle, the quality of aquatic products depends on circulation time, temperature and tolerance of the product itself. Because the tolerance is determined by the biological characteristics of aquatic products, it is an uncontrollable factor in cold-chain logistics. We only consider the influence of circulation time and temperature on the aquatic products cold-chain logistics. The circulation time and temperature are determined by the equipment and operational level of node enterprises in the cold-chain logistics, also affects the operating costs of node enterprises in the cold-chain logistics. Moreover, the quality of aquatic products determines customer satisfaction and reflects the appeal of public. So, the quality indexes are important in the evaluation on aquatic products cold-chain logistics.

\subsubsection{Customer Indicators}

Since the downstream enterprises are customers of the upstream ones in a supply chain, customers here mean the downstream enterprises. The target of aquatic products cold-chain logistics is to achieve customer's satisfaction. Customers' satisfaction depends on their expectation for the product or service as well as their actual experience of the product or service. A customer is satisfactory when the actual experience meets his expectations. The satisfaction will be very strong when the actual experience exceeds their expectations and the customers may purchase again. If the actual experience is below their expectations, customers are unsatisfied and lost. Of course, customers' satisfaction ultimately depends on the better customer value provided by the company than its competitors. For cold-chain logistics, aquatic products' quality, sale price, and service in purchasing (such as order fulfillment) are important factors in creating customer value.

\subsubsection{Supply Chain Indicators}

The supply chain is a value chain based on longitudinal integration in which the economic interests are connected and the business relationship is close. Compared with the longitudinal integration, the enterprises in the supply chain are relatively independent stakeholders, the organization is relatively loose, management philosophy and values of individual enterprises are different and even conflicting. They are unable to operate under a unified organizational system, because the supply chain is a virtual enterprise with a larger scope. So the relationship between the enterprises in a supply chain is synergistic relationship rather than control relationship. Only through collaboration, all subjects and processes of supply chain are able to achieve seamless connection, and then the supply chain can form a whole organic and 
be called "chain" indeed. In aquatic products cold-chain logistics, only close collaboration can ensure that the products are under optimum temperature environment in the entire logistics process and cut all unnecessary retention time, and ultimately guarantee the quality safety of aquatic products. Also, collaboration benefits to the reduction of logistics loss and reduce energy consumption. The supply chain indicators mainly refer to the supply chain collaboration indicators, including four aspects: strategic collaboration, process collaboration, information collaboration and technology collaboration.

\subsubsection{Social Indicators}

From the level of the whole society, shorter time as far as possible of aquatic products circulating from water to dinner table, the quality stability in the logistics, fewer logistics links, lower loss in entire logistics process, better logistics efficiency, lower energy consumption in the logistics process, and lower comprehensive logistics costs, etc., are the focus of the public. The ultimate purpose of public concerning aquatic products cold-chain logistics is to improve terminal consumer satisfaction and improve people's livelihood.

\subsubsection{Node Enterprises of Supply Chain Indicators}

Internally, the quality and cost are the focus of node enterprises. The quality affects the product price and income. Equipment investment, utilization efficiency (asset management), and logistics operations are critical factors in the costs. Then, revenue and final costs determine the profits. Externally, the node enterprises are the ultimate bearer and coordinator of the different subjects. Because of the "Trade-off" law, which means a contradiction between costs and quality, the node enterprises, as the final implementation subjects of the aquatic products cold-chain logistics, must bear this relationship, and play the role as the ultimate bearers and coordinators of supply chain participants. However, there are certain causality and consistency between many subjects' expectations and goals, which can alleviate the degree of conflicts in a certain extent. For example, node enterprises' behaviors to improve logistics efficiency, reduce logistics costs, cut total logistics loss down, guarantee product quality, and improve customer satisfaction, not only help to increase profits and enhance competitiveness, but also consistent with the public's value orientation.

\subsection{Calculation Method for Performance Evaluation}

The determination of indexes weights is the prerequirements for performance evaluation. ANP (Analytic Network Process) method is a composite of qualitative and quantitative method. It 
reflects both objectivity and the decision maker's preferences, but the determination of paired comparison matrix has certain arbitrariness. Entropy method is a purely quantitative weight assigning approach. So, this paper uses the entropy method to correct weights derived from ANP.

Fuzzy comprehensive evaluation method uses fuzzy math to make an overall assessment of things or objects constrained by variety of factors, it can better resolve ambiguous and hardto-quantify problems. This paper first uses ANP and entropy method to determine the evaluation index weights, and then use the fuzzy comprehensive evaluation method to evaluate the performance of the empirical enterprise from 2008 to 2012. The steps of calculation method are as follows.

\subsubsection{Calculating Weight by ANP Method}

Use ANP method to calculate the weights which will be introduced it in Section 4.

\subsubsection{Calculating Weight by Entropy Method}

Let the proportion of index $j$ and evaluation object $i$ be $p_{i j}=y_{i j} / \sum_{i=1}^{m} y_{i j}$, where $m$ is the number of the evaluation objects. Let the entropy of index $j$ be $e_{j}=-k \sum_{i=1}^{m}\left(p_{i j}{ }^{*} \ln p_{i j}\right), k=1 / \ln m$. Then, the entropy weight of index $j$ is $w_{j}=\left(1-e_{j}\right) / \sum_{j=1}^{n}\left(1-e_{j}\right)$.

\subsubsection{Calculating the Combined Weight}

Let $\alpha_{j}$ be the weight gotten by ANP, then $\beta_{j}=\left(\alpha_{j} * w_{j}\right) / \sum_{j=1}^{n}\left(\alpha_{j}{ }^{*} w_{j}\right)$ is the combined weight.

\subsubsection{Fuzzy Comprehensive Evaluation}

First, we determine the factor-set and appraisal-set. Assuming that there are $m$ evaluation indexes, we mark $U=\left\{u_{1}, u_{2}, \ldots, u_{\mathrm{m}}\right\}$ as the factor-set of the evaluation objects. The appraisalset is a set consists of all the possible values of evaluation indexes, and it is represented by $V=\left\{v_{1}, v_{2}, \ldots, v_{\mathrm{n}}\right\}$. Second, we establish the membership grade of each element in factor-set to the element in the appraisal-set. The representation of an evaluation object in index $u_{i}$ can be described by a fuzzy evaluation vector $r_{i}=\left(r_{i 1}, r_{i 2}, \ldots, r_{i \mathrm{~m}}\right)$, and all the fuzzy evaluation vectors 
constitute a fuzzy evaluation matrix $R=\left(\begin{array}{cccc}r_{11} & r_{12} & \cdots & r_{1 n} \\ r_{21} & r_{22} & \cdots & r_{2 n} \\ \vdots & \vdots & \ddots & \vdots \\ r_{m 1} & r_{m 2} & \cdots & r_{n n}\end{array}\right)$, where $r_{i}=(i=1,2, \ldots, m ; j=1,2, \ldots, n)$ is the membership grade of the index $u_{i}$ against $v_{j}$. Third, let $A=\left(a_{1}, a_{2}, \ldots, a_{i}, a_{\mathrm{m}}\right)$ be the weight vector of the evaluation indexes. Selecting proper operator to composite weight vector $A$ and matrix $\mathrm{R}$, we can get $B=A \circ R=\left(b_{1}, b_{2}, \ldots, b_{n}\right)$. Fourth, assign the elements in appraisal-set a special score, we can get $V^{\prime}=\left\{v_{1}^{\prime}, v_{2}^{\prime}, \ldots, v_{n}^{\prime}\right\}$. Multipling vector $\mathrm{B}$ with $V^{\prime}$ to get the comprehensive evaluation scores of each evaluation object. The object with highest comprehensive score performs the best.

\section{Empirical Research}

\subsection{Overview of the Empirical Object}

Shandong Oriental Ocean Sci-Tech Co., Ltd. in Yantai, Shandong is a national high-tech enterprise operating aquaculture, refrigerated processing and storage, scientific research promotion and international trade. Its frozen food processing plant is hailed as " the most distinctive food processing plants in Asia," and it is now the benchmark enterprise in agriculture products processing industry in China. For commercial confidentiality reasons, we can only get the aquatic products cold-chain processing data. Then we evaluate the performance of its cold-chain logistics by using the actual data of aquatic products cold-chain from 2008 to 2012. The data are shown in Table 1.

\subsection{Construction of Evaluation Indexes}

According to the ACSSN model in Section 3, the three levels evaluation indexes system from aquatic products, clients, supply chain, society, and node enterprises are shown in Table 1. 


\begin{tabular}{|c|c|c|c|c|c|c|c|c|}
\hline \multirow{2}{*}{ Level 1} & \multirow{2}{*}{ Level 2} & \multirow{2}{*}{ Level 3} & \multirow{2}{*}{ No } & \multicolumn{5}{|c|}{ Years } \\
\hline & & & & 2008 & 2009 & 2010 & 2011 & 2012 \\
\hline \multirow{5}{*}{$\begin{array}{l}\text { Aquatic } \\
\text { Product }\end{array}$} & Time & Average processing time (days) & $\times 11$ & 28 & 23 & 16 & 19 & 12 \\
\hline & Temperature & Temperature compliance rate (\%) & $\mathrm{X} 12$ & 92 & 92.80 & 92.50 & 92 & 92.80 \\
\hline & \multirow{3}{*}{ Quality } & Raw materials pass rate (\%) & $\times 13$ & 96 & 98 & 100 & 99 & 100 \\
\hline & & Batch detection rate (\%) & $X 14$ & 90 & 92.5 & 96 & 98 & 100 \\
\hline & & Batch qualified rate (\%) & $\times 15$ & 99.70 & 99.20 & 99.50 & 99.60 & 99.40 \\
\hline \multirow{6}{*}{ Customer } & \multirow{3}{*}{$\begin{array}{l}\text { Order } \\
\text { Fulfillment }\end{array}$} & Timely delivery rate (\%) & $\times 21$ & 98.40 & 99.20 & 97.50 & 98.80 & 99.40 \\
\hline & & Order fulfillment rate (\%) & $\times 22$ & 99.30 & 99.80 & 99.40 & 99.60 & 99.20 \\
\hline & & Customer order lead time (days) & $\times 23$ & 45 & 38 & 55 & 40 & 67 \\
\hline & \multirow{3}{*}{$\begin{array}{l}\text { Customer } \\
\text { Service }\end{array}$} & Customer satisfaction rate (\%) & $\times 24$ & 97.70 & 96.80 & 98.20 & 97.40 & 95.60 \\
\hline & & Customer feedback process rate (\%) & $\times 25$ & 98.4 & 93.8 & 99 & 97.6 & 99.7 \\
\hline & & Customer churn rate (\%) & $\times 26$ & 2.3 & 0 & 1.6 & 0.7 & 0.9 \\
\hline \multirow{5}{*}{$\begin{array}{l}\text { Supply } \\
\text { Chain }\end{array}$} & Strategic & Degree of strategic trust & $\times 31$ & 0.6 & 0.8 & 0.7 & 0.8 & 0.9 \\
\hline & \multirow{2}{*}{ Information } & Information sharing ratio (\%) & $\times 32$ & 92 & 93 & 100 & 97 & 100 \\
\hline & & Information sharing accuracy (\%) & $\times 33$ & 100 & 98.6 & 100 & 99.3 & 100 \\
\hline & Process & Process convergence smoothness & $\times 34$ & 0.6 & 0.7 & 0.9 & 0.8 & 0.9 \\
\hline & Technology & Technical Compatibility & $\times 35$ & 0.6 & 0.6 & 0.7 & 0.8 & 0.8 \\
\hline \multirow{2}{*}{ Society } & Energy & Energy cost per unit (Yuan) & $X 41$ & 564.1 & 617.9 & 699.4 & 645.9 & 664.1 \\
\hline & Price Change & The factory purchase price rate (\%) & $\times 42$ & 130 & 128 & 143 & 137 & 135 \\
\hline \multirow{6}{*}{$\begin{array}{l}\text { Node } \\
\text { Enterprise }\end{array}$} & \multirow{3}{*}{ Cost } & Equipment depreciation cost rate (\%) & $\times 51$ & 1.04 & 1.60 & 1.31 & 1.15 & 1.15 \\
\hline & & Labor cost rate (\%) & $\times 52$ & 5.15 & 8.89 & 7.54 & 8.54 & 16.58 \\
\hline & & Cost raisingper $20 \%$ yield raising (\%) & $\times 53$ & 1.90 & 2.62 & 2.32 & 2.38 & 4.08 \\
\hline & \multirow{3}{*}{$\begin{array}{l}\text { Asset } \\
\text { Management }\end{array}$} & Equipment utilization (\%) & $\times 54$ & 81.30 & 81 & 81.60 & 80.80 & 81.90 \\
\hline & & Return on investment (\%) & $\times 55$ & 2.16 & 5.33 & 0.78 & 3.50 & 10.40 \\
\hline & & Turnover (\%) & $\times 56$ & 80.78 & 56.21 & 68.05 & 81.04 & 83.41 \\
\hline
\end{tabular}

Table 1. The evaluation indexes and the operation data of the example enterprise 


\subsection{Calculation of Performance Evaluation}

\subsubsection{Data Normalization}

The form of raw evaluation data listed in Table 1 cannot meet the requirements of relevant evaluation methods. Therefore, we need to normalize the raw data.

For efficiency-type indexes $y_{i j}=\frac{x_{i j}-\min _{1 \leq i \leq m} x_{i j}}{\max _{1 \leq i \leq m} x_{i j}-\min _{1 \leq i \leq m} x_{i j}} * \alpha+(1-\alpha) \quad(1 \leq i \leq m)$

For cost-type indexes $y_{i j}=\frac{\max _{1 \leq i \leq m} x_{i j}-x_{i j}}{\max _{1 \leq i \leq m} x_{i j}-\min _{1 \leq i \leq m} x_{i j}} * \alpha+(1-\alpha) \quad(1 \leq i \leq m)$

The data after normalizing are shown in Table 2.

\begin{tabular}{|c|c|c|c|c|c|}
\hline \multirow{2}{*}{ Indexes } & \multicolumn{5}{|c|}{ Years } \\
\hline & 2008 & 2009 & 2010 & 2011 & 2012 \\
\hline $\mathrm{X} 11$ & 0.100 & 0.381 & 0.775 & 0.606 & 1.000 \\
\hline $\mathrm{X} 12$ & 0.100 & 1.000 & 0.663 & 0.100 & 1.000 \\
\hline $\mathrm{X} 13$ & 0.100 & 0.550 & 1.000 & 0.775 & 1.000 \\
\hline$X 14$ & 0.100 & 0.325 & 0.640 & 0.820 & 1.000 \\
\hline X15 & 1.000 & 0.100 & 0.640 & 0.820 & 0.460 \\
\hline $\mathrm{X} 21$ & 0.526 & 0.905 & 0.100 & 0.716 & 1.000 \\
\hline$x 22$ & 0.250 & 1.000 & 0.400 & 0.700 & 0.100 \\
\hline$x 23$ & 0.783 & 1.000 & 0.472 & 0.938 & 0.100 \\
\hline$X 24$ & 0.827 & 0.515 & 1.000 & 0.723 & 0.100 \\
\hline$X 25$ & 0.802 & 0.100 & 0.893 & 0.680 & 1.000 \\
\hline$x 26$ & 0.100 & 1.000 & 0.374 & 0.726 & 0.648 \\
\hline$\times 31$ & 0.100 & 0.700 & 0.400 & 0.700 & 1.000 \\
\hline X32 & 0.100 & 0.213 & 1.000 & 0.663 & 1.000 \\
\hline X33 & 1.000 & 0.100 & 1.000 & 0.550 & 1.000 \\
\hline X34 & 0.100 & 0.400 & 1.000 & 0.700 & 1.000 \\
\hline$\times 35$ & 0.100 & 0.100 & 0.550 & 1.000 & 1.000 \\
\hline$X 41$ & 1.000 & 0.642 & 0.100 & 0.456 & 0.335 \\
\hline$x 42$ & 0.880 & 1.000 & 0.100 & 0.460 & 0.580 \\
\hline$\times 51$ & 1.000 & 0.100 & 0.566 & 0.823 & 0.823 \\
\hline$\times 52$ & 1.000 & 0.706 & 0.812 & 0.733 & 0.100 \\
\hline$\times 53$ & 1.000 & 0.703 & 0.827 & 0.802 & 0.100 \\
\hline$\times 54$ & 0.509 & 0.264 & 0.755 & 0.100 & 1.000 \\
\hline$\times 55$ & 0.229 & 0.526 & 0.100 & 0.354 & 1.000 \\
\hline$\times 56$ & 0.913 & 0.100 & 0.492 & 0.922 & 1.000 \\
\hline
\end{tabular}

Table 2 The data after normalizing 


\subsubsection{Determining the Evaluation Index Weights}

1) Using ANP to Calculate Weights

ANP method (Analytic Network Process), which is based on the AHP (Analytic Hierarchy Process), takes into account the interaction between the various factors or adjacent level, uses "super-matrix" to conduct comprehensive analysis of various interacting factors, and gets the mixed weights. Since the calculation of "super-matrix" in ANP method is extremely timeconsuming, it must be completed by using computer software. The author uses Super Decisions software.

We construct the network model in Super Decisions, which is depicted in Figure 3. Each element-group in Figure 3 represents the level 2 indexes shown in Table 1 . The elements in each element-group represent the level 3 indexes which are related with level 2 indexes. The connection lines represent the relationships between different elements. The internal connection lines in some element groups such as quality,

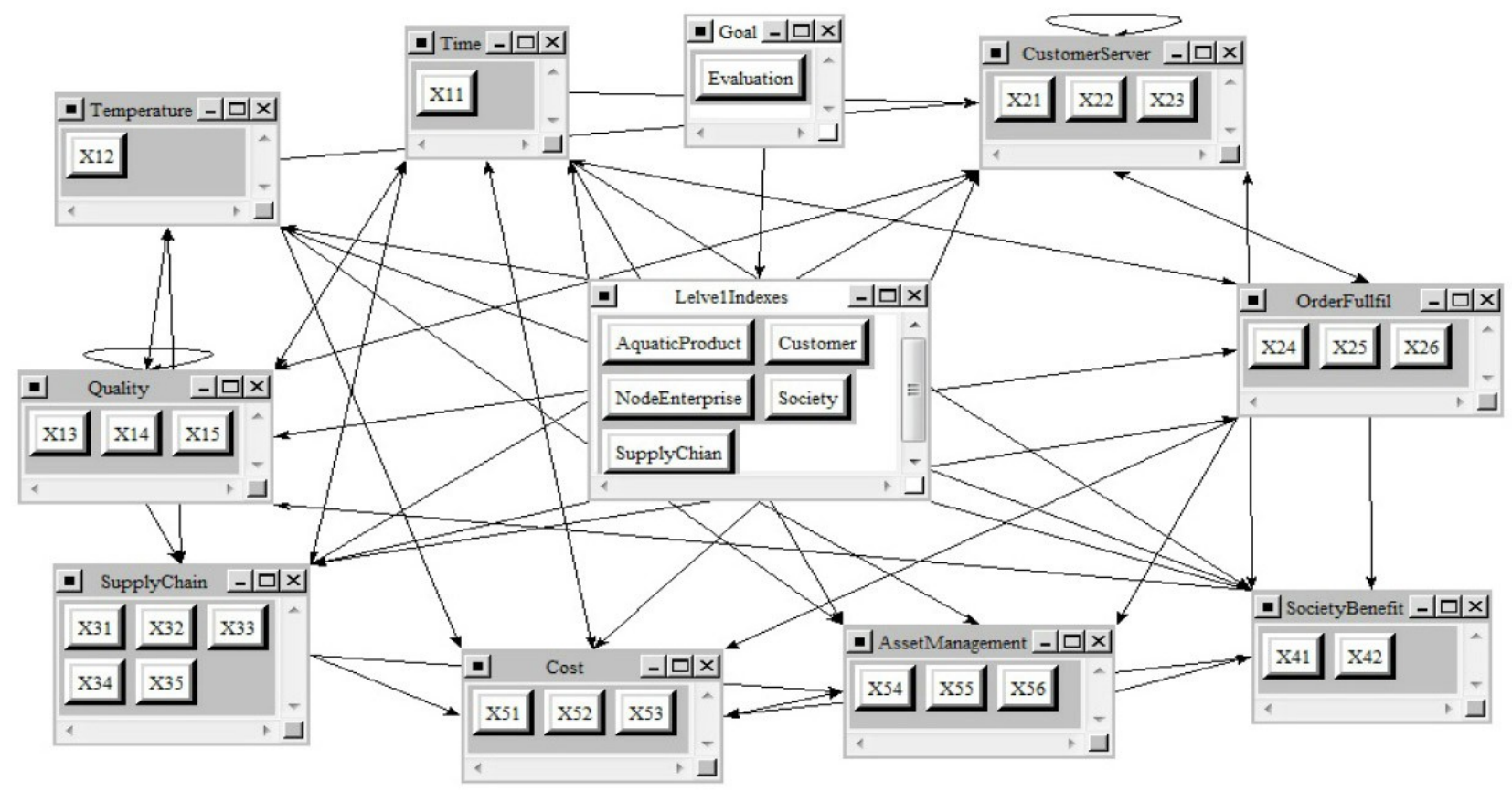

Figure 3. The ANP model of evaluation indexes

customer service illustrate that there are internal dependencies in those element-groups. Then we input paired comparison matrix, and the software automatically calculate the final weight. The final index weights are shown in Table 3. 
2) Using Entropy Method to Revise the Weights

According to the method described in Section 3.5, after being corrected by entropy method, we get the final combination weight, which is shown in Table 3.

\begin{tabular}{|c|c|c|c|c|c|r|r|}
\hline Index & ANP & Entropy & Final & Index & ANP & Entropy & \multicolumn{1}{l|}{ Final } \\
\hline X11 & 0.079 & 0.039 & 0.075 & X32 & 0.033 & 0.054 & 0.043 \\
\hline X12 & 0.092 & 0.068 & 0.152 & X33 & 0.023 & 0.036 & 0.020 \\
\hline X13 & 0.051 & 0.035 & 0.044 & X34 & 0.016 & 0.041 & 0.016 \\
\hline X14 & 0.011 & 0.042 & 0.011 & X35 & 0.008 & 0.070 & 0.014 \\
\hline X15 & 0.144 & 0.036 & 0.127 & X41 & 0.008 & 0.043 & 0.008 \\
\hline X21 & 0.067 & 0.035 & 0.057 & X42 & 0.084 & 0.038 & 0.077 \\
\hline X22 & 0.041 & 0.051 & 0.051 & X51 & 0.069 & 0.033 & 0.056 \\
\hline X23 & 0.063 & 0.037 & 0.056 & X52 & 0.017 & 0.031 & 0.013 \\
\hline X24 & 0.022 & 0.034 & 0.018 & X53 & 0.046 & 0.031 & 0.035 \\
\hline X25 & 0.024 & 0.032 & 0.019 & X54 & 0.028 & 0.047 & 0.032 \\
\hline X26 & 0.017 & 0.039 & 0.016 & X55 & 0.018 & 0.054 & 0.024 \\
\hline X31 & 0.015 & 0.037 & 0.014 & X56 & 0.024 & 0.037 & 0.021 \\
\hline
\end{tabular}

Table 3. Weights of evaluation indexes

\subsubsection{Fuzzy Comprehensive Evaluation}

1) Determine the factor-set and appraisal-set of evaluation objects. Establish factor-set in accordance with the evaluation indexes shown in Table 1 . We denote it by $U=\left\{u_{1}, u_{2}, \ldots, u_{24}\right\}$. The appraisal-set is divided into five grades according to the performance level: excellent, good, fair, poor, and very poor, and we denote it by $V=\left\{v_{1}, v_{2}, v_{3}, v_{4}, v_{5}\right\}$.

2) Determine the membership grade functions. Uses $(1,0.75,0.5,0.25,0)$ to present excellent, good, fair, poor, and very poor in the appraisal-set. We denote it by $V=(1,0.75,0.5,0.25,0)$. Select the normal membership grade function $\mu_{a}=e^{-\left(\frac{x-a}{\sigma}\right)^{2}},(a=1,0.75,0.5,0.25,0)$ as the membership grade function of each index to appraisal-set. Here, the $\sigma$ is the standard deviationing appraisal-set values.

3) Construct fuzzy judgment matrix. According to the membership grade equation, calculate the membership grade of each index value in Table 2 to excellent, good, fair, poor, and very poor. Make the normalization processing in accordance with $y_{i j}=x_{i j} /\left(\sum_{j=1}^{n} x_{i j}\right) \quad(1 \leq i \leq m=24,1 \leq j \leq n=5)$, and construct fuzzy judgment matrix for five years (denoted by $R_{1} \ldots R_{5}$ ). Due to the space limitation, the calculation process of five fuzzy judgment matrix is omitted. 
4) Conduct the multivariate fuzzy evaluation. We denoted the weight vector from Table 3 by $A=(0.075,0.152,0.044, \ldots, 0.035,0.032,0.024,0.021)$, select M $(.++)$ operator to carry compositional calculation for weight vector A and five fuzzy judgment matrix, we get

$B_{1}=A \circ R_{1}=(0.226,0.204,0.161,0.214,0.196), B_{2}=A \circ R_{2}=(0.249,0.219,0.180,0.199$, $0.153)$,

$B_{3}=A \circ R_{3}=(0.192,0.286,0.258,0.169,0.095), B_{4}=A \circ R_{4}=(0.201,0.307,0.242,0.154$, 0.097),

$B_{5}=A \circ R_{5}=(0.343,0.272,0.165,0.129,0.091)$.

5) Calculate comprehensive evaluation scores of five years. Assign the fuzzy appraisal-set, $V$ $'=(10,8,6,4,2)$, multiple vector $B$ with $V^{\prime}$, and get the comprehensive evaluation scores of five years:

$G_{1}=B_{1} V^{\prime T}=6.101, G_{2}=B_{2} V^{\prime T}=6.424, G_{3}=B_{3} V^{\prime T}=6.622, G_{4}=B_{4} V^{\prime T}=6.721, G_{5}=B_{5} V^{\prime T}=7.296$.

From the above, we can see that the performance in 2012 is the best (7.296), performance in 2008 is the worst (6.101). This implies that the performance of the enterprise has been continuously improved.

\section{Performance Improvement Measures Simulation}

As stated above, the original purpose of performance evaluation is to improve the performance. Based on the evaluation process and results stated in the previous section, we propose a performance improvement measure and a model to simulate its performance.

The foregoing " $3 \mathrm{~T}$ " principle shows that the circulation temperature and circulation time are the decisive factors of aquatic products quality. As we know, the lower circulation temperature can keep the quality of aquatic products for a longer period. Thus, the temperature is the most fundamental factor to ensure the quality of aquatic products.

It is well known that the lower the temperature is, the better is the product quality and the higher is the aquatic products cold-chain logistics performance level. However, maintaining lower temperature increases the costs and decreases the profits. The nature of the enterprises is to pursues the profits. Hence we need to conduct a simulation experiment to show that lowing logistics temperature is really able to benefit the enterprise.

System dynamics is an important method to solve the problems which have dynamic changes with time and the problems which have feedback relationship. System dynamics can be used for the dynamic prediction of complex system by simulation, and it has been widely used in the economic, management, social and other fields. We construct a system dynamics simulation 
model, take frozen cod for example, to study the impact of maintaining lower temperature environment against the profit of the enterprise.

\subsection{System Dynamics Model}

\subsubsection{System Flow Diagram}

We use Vensim software to build the system dynamics model, which includes four state variables: the inventory costs, the cumulative loss of quality, the retailer's inventory, and the sale volume, and four rate variables: stock cost rate, quality loss rate, order rate and selling rate. The retailer's inventory is jointly decided by the positive feedback loop of order and negative feedback loop of sales, and induce the retailer to stock inventory at the desired level; the inventory costs is decided by the positive feedback loop, the retailer inventory level, and the storage time; the accumulated quality loss is decided by the two positive feedback loops inventory temperature and inventory time. The profit is determined by the positive feedback of sales and the negative feedback of various types of costs. The system flow diagram reflects the relation between the variables in the model, represents also the structure form in detail, and is an important step for system dynamics modeling using Vensim. The flow diagram is shown in Figure 4.

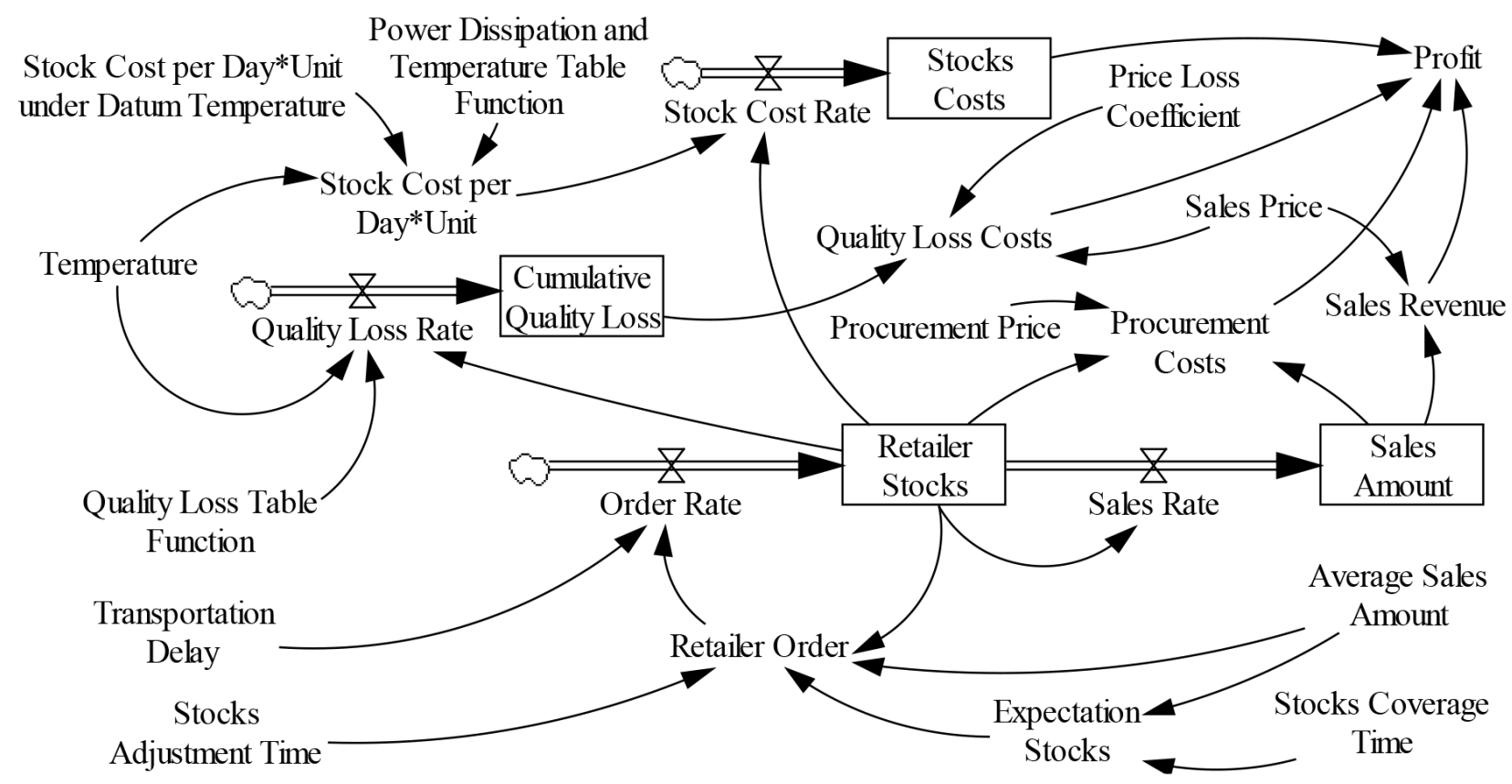

Figure 4. The flow diagram of aquatic product cold-chain sales 


\subsubsection{Model Equations}

1) State Equations

Retailer Stocks $=$ INTEG (Order Rate - Sales Rate, 0$)$

Sales Amount $=$ INTEG $($ Sales Rate, 0$)$

Stocks Cost $=$ INTEG $($ Stock Cost Rate, 0$)$

Cumulative Quality Loss = INTEG (Quality Loss Rate, 0 )

2) Rate Equations

Order Rate $=$ DELAY3 (Retailer Order, Transportation Delay)

Sales Rate $=$ IF THEN ELSE (Retailer Stocks $>$ Average Sales Amount, Average Sales Amount + RANDOM NORMAL $(-2,2,0,2,1), 0)$

Stock Cost Rate $=$ Stock Cost per day*Retailer Stocks

Quality Loss Rate $=$ Quality Loss Table function (Temperature)*Retailer Stock

3) Some auxiliary equation

Profit $=$ Sales Revenue - Stocks Costs - Quality Loss Costs - Procurement Costs

Sales revenue $=$ Sales Price*Sales Amount

Quality Loss Costs =Cumulative Quality Loss*Sales Price*Price Loss Coefficient

Procurement Costs $=($ Retailer Stocks + Sales Amount $) *$ Procurement Price

Retailer order $=\operatorname{Max}(0,($ Expectation Stocks - Retailer Stocks) $/$ Stocks Adjustment Time + Average sales Amount)

Expectation Stocks $=$ Average Sales Amount*Stocks Coverage Time 


\subsubsection{Parameters Setting}

1) Quality loss table function

This model does not consider the loss of quality generated in the upstream of cod cold-chain logistics (the purchase price varies from different quality). For simplicity, we represent the profit decrease by multiplying total quality loss and price loss coefficient in the simulation period.

2) Temperature-energy consumption relationship table function

Although the energy consumption varies from different refrigeration equipment used by sales companies, the system power consumption is definitely increasing as the temperature decreases, and power consumption will increase significantly in order to obtain a lower temperature after reaching a certain temperature. Here the approximative power consumption coefficient ratio at each temperature is adopted from Lu and Wang (2012), which is shown in Table 4.

\begin{tabular}{|l|r|r|r|r|r|}
\hline Temperature $\left({ }^{\circ} \mathrm{C}\right)$ & -10 & -18 & -25 & -34 & -40 \\
\hline Energy Consumption Ratio & 0.84 & 1 & 1.17 & 1.55 & 1.97 \\
\hline
\end{tabular}

Table 4. Energy consumption ratio of refrigeration equipment under different temperature

3) Some auxiliary variables and constant values

\begin{tabular}{|c|c|c|c|c|c|}
\hline $\begin{array}{c}\text { Procurement } \\
\text { Price }\end{array}$ & Sales Price & $\begin{array}{c}\text { Price Loss } \\
\text { Coefficient }\end{array}$ & $\begin{array}{c}\text { Average Sales } \\
\text { per Day }\end{array}$ & $\begin{array}{c}\text { Transportatio } \\
\text { n Delay }\end{array}$ & $\begin{array}{c}\text { Stocks } \\
\text { Coverage Time }\end{array}$ \\
\hline 140 Yuan $/ \mathrm{Kg}$ & 200 Yuan $/ \mathrm{Kg}$ & 0.2 & $10 \mathrm{Kg} / \mathrm{Day}$ & $2 \mathrm{Day}$ & $20 \mathrm{Day}$ \\
\hline
\end{tabular}

Table 5. The variable and constant value of model

\subsection{Model Simulation}

The simulation experiment is carried in the platform Vensim, the simulation time is set as 180 days, and the simulation step is set as one day. The temperature is set respectively at $-30^{\circ} \mathrm{C}$, $-18^{\circ} \mathrm{C}$, and $-10^{\circ} \mathrm{C}$. The results are depicted in Figure 5. From Figure 5, the profit level of coldchain sales enterprises is negatively correlated with the inventory temperature, that is, the lower the temperature is, the higher is the profit level. This is inconsistent with the "Trad-off" principle. The fact is, this result hides the effects of inventory cost and quality loss cost. The 
decrease of quality loss cost is greater than the increase of inventory cost. This lead a higher profit level at $-30^{\circ} \mathrm{C}$ than it at $-10^{\circ} \mathrm{C}$.

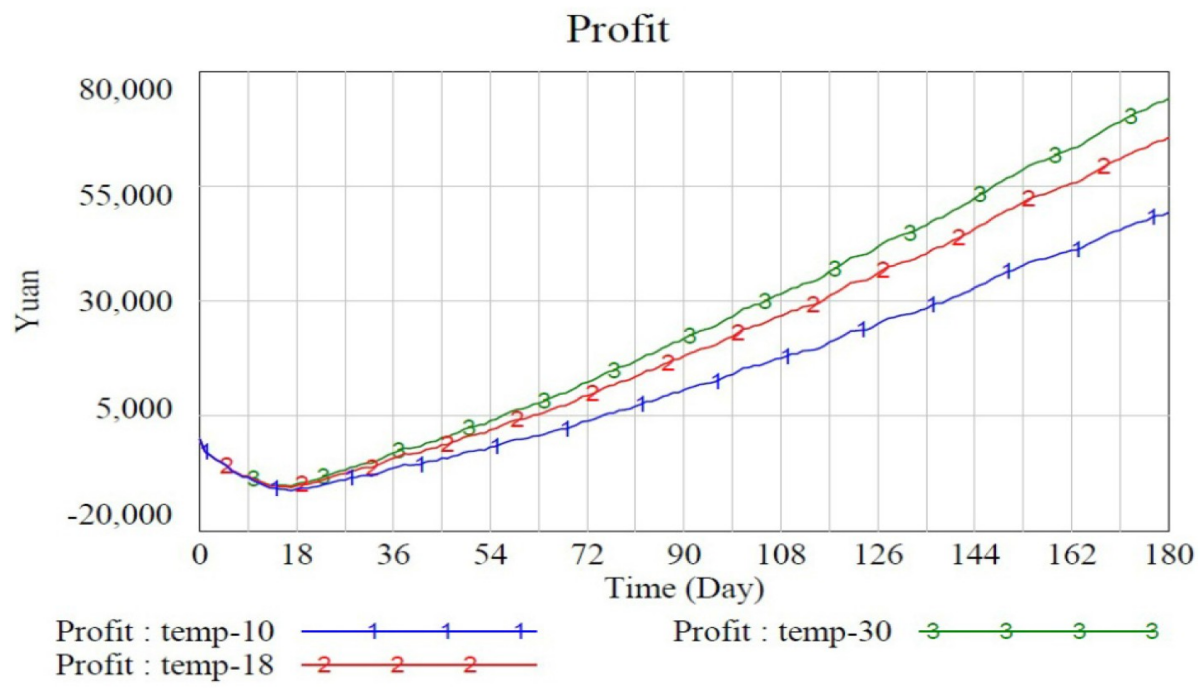

Figure 5. The influence of different temperature against profit

\section{Conclusions}

The low-level cold-chain logistics performance is one of the important reasons leading to that aquatic products consumption and supply do not match in China. Through the analysis and research of this paper, the conclusions are as follows:

(1) Based on the analysis of the particularity of the aquatic products cold-chain logistics, combined with the traditional performance evaluation system, we first propose the SISP model of performance evaluation system and ACSSN model of evaluation indexes. Then we apply a fuzzy comprehensive evaluation method to evaluate operational performance of an aquatic products enterprise in China and propose an improvement measure of reducing the logistics temperature. Also we construct a system dynamics model to simulate its performance.

(2) The performance evaluation indexes should follow principle of systematicness, completeness and harmony so that different goals and interests of the different subjects and links can be embodied. Aquatic products, customer, society, supply chain and the node enterprises of supply chain are the subjects and objects of aquatic product cold-chain logistics. Designing the performance evaluation indexes from the five aspects can comprehensively measure performance level of the aquatic products cold chain logistics, and balance their goals and pursuits. It's important to point out that the dimension of aquatic product is the core, and the other four dimensions serve the dimension of aquatic product. That is to say, ensuring the quality of aquatic products is the primary goal of aquatic products cold chain logistics. 
(3) The performance improvement is an essential part of performance evaluation. Maintaining low temperature environment is one of the most important ways to improve the performance level of the aquatic products cold chain logistics. But in order to get high profits, it is necessary to balance low temperature and cost. Through the simulation of system dynamics, we find that the profit increases as the temperature decreases under the reasonable temperature range. That is, the performance improvement measure of decreasing temperature can really improve the performance level of aquatic products cold chain logistics.

\section{Acknowledgements}

This paper is the research finding sponsored by National Science and Technology Support Projects (2012BAD38B08, 2014BAL07B01).

\section{References}

Aramyan, L.H., Oude Lansink, A.G.J.M., van der Vorst, J.G.A.J, \& van Kooten, O. (2007). Performance measurement in agri-food supply chains: A case study. Supply Chain Management, 12(4), 304-315. http://dx.doi.org/10.1108/13598540710759826

Dabbene, F., Gay, P., \& Sacco, N. (2008). Optimisation of Fresh-food Supply Chains in Uncertain Environments, Part I: Background and Methodology. BIOSYSTEMS ENGINEERING, 99(3), 360-371. http://dx.doi.org/10.1016/j.biosystemseng.2007.11.012

Bowersox, D.J. (1996). Logistical Management: The Integrated Supply Chain Process. McGrawHill.

Fawcett, S.E., \& Cooper, M.B. (1998). Logistics Performance Measurement and Customer Success. Industrial Marketing Management, 27(4), 341-357. http://dx.doi.org/10.1016/S00198501(97)00078-3

Garcia, F.A., Marchetta, M.G., \& Camargo, M. (2012). A framework for measuring logistics performance in the wine industry. International Journal of Production Economics, 135(1), 284-298. http://dx.doi.org/10.1016/j.ijpe.2011.08.003

Jacxsens, L., Luning, P.A., Marcelis, W.J., \& van Boekel, T. (2011). Tools for the performance assessment and improvement of food safety management systems. Trends in Food Science \& Technology, 22(11), S80-S89. http://dx.doi.org/10.1016/j.tifs.2011.02.008

Jacxsens. L., Uyttendaele, M., \& Devlieghere, F. (2010). Food Safety Performance Indicators to Benchmark Food Safety Output of Food Safety Management Systems. International Journal of Food Microbiology, 141(4), S180-S187. http://dx.doi.org/10.1016/j.ijfoodmicro.2010.05.003 
Joshi, R., Banwet, D.K., \& Shankar, R. (2011). A Delphi-AHP-TOPSIS based Benchmarking Framework for Performance. Expert Systems with Applications, 38(8), 10170-10182. http://dx.doi.org/10.1016/j.eswa.2011.02.072

Lu Y.Z., \& Wang D. (2012). Energy-saving Analysis of CO2 Low Temperature Freeze and Cold Storage System. Refrigeration and Air-conditioning, 10(5), 23-27.

Sun, C., Wang, J., \& Zhang, H. (2015). Comparative analysis of residents consumption level and consumption characteristics for aquatic products in Chinese big city. Chinese Agricultural Science Bulletin, 31(8), 86-92.

van Donselaar. K.H., \& Broekmeulen, R.A. (2012). Approximations for the Relative Outdating of Perishable Products by Combining Stochastic Modeling, Simulation and Regression Modeling. International Journal of Production Economics, 140(2), 660-669.

http://dx.doi.org/10.1016/j.ijpe.2012.02.023

Wong, W.P. (2008). A Review on Benchmarking of Supply Chain Performance Measures. Benchmarking: An International Journal, 15(1), 25-51.

http://dx.doi.org/10.1108/14635770810854335

Zanoni, S., \& Zavanella, L. (2012). Chilled or Frozen? Decision Strategies for Sustainable Food Supply Chains. International Journal of Production Economics, 140(2), 731-736. http://dx.doi.org/10.1016/j.ijpe.2011.04.028

Journal of Industrial Engineering and Management, 2015 (www.jiem.org)

Article's contents are provided on an Attribution-Non Commercial 3.0 Creative commons license. Readers are allowed to copy, distribute and communicate article's contents, provided the author's and Journal of Industrial Engineering and Management's names are included. It must not be used for commercial purposes. To see the complete license contents, please visit http://creativecommons.org/licenses/by-nc/3.0/. 